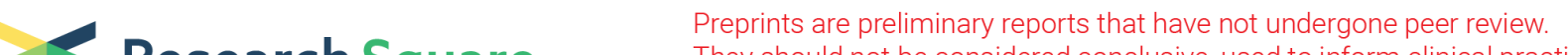 Research Square They should not be considered conclusive, used to inform clinical practice, or referenced by the media as validated information.
}

\section{Male Gender is A Risk Factor For Sever Form of COVID-19 Illness and Worse Outcome in The Middle East}

Ibrahim Y Hachim

University of Sharjah College of Health Sciences

Mahmood Y Hachim

Mohammed Bin Rashid University of Medicine and Health Sciences

Kashif Bin Naeem

University of Sharjah College of Medicine

Haifa Hannawi

Kementerian Kesihatan Malaysia

Issa Al Salmi

The Royal Hospital, Muscat, Oman

Suad Hannawi ( $\sim$ suad1@ausdoctors.net)

Emirates Ministry of Health https://orcid.org/0000-0002-5689-6710

\section{Research Article}

Keywords: COVID-19, male gender, risk factor, respiratory infection, pandemic

Posted Date: June 17th, 2020

DOl: https://doi.org/10.21203/rs.3.rs-35439/v1

License: (c) (i) This work is licensed under a Creative Commons Attribution 4.0 International License. Read Full License 


\section{Abstract}

The identification of risk-factors, predicting the disease severity and outcome in novel coronavirusdisease-19 (COVID-19) patients, is essential to improve responsiveness to this pandemic.

The association between gender and wide-range of clinical, pathological, and epidemiological factors was studied in 200-patients recruited during March-April 2020.

A higher prevalence of COVID-19 infection in male (72\%) compared to females (28\%). Age and history of previous comorbidities were nearly comparable between genders ( $P$ value 0.75 and 0.97 , respectively), male-patients had higher incidence of sever-critical form of the disease (44.67\%) compared to only $23.22 \%$ in female-patients $(P<0.001)$. A $26.39 \%$ and $1.79 \%$ of male and female patients needed Intensive-care-unit $(\mathrm{ICU})$ admission $(P<0.001)$, respectively.

Male-patients developed a significant higher rate of lung injury presented as bilateral airspace consolidation in the plain chest $\mathrm{X}$-ray at admission (38.89\%) compared to $23.21 \%$ in female patient $(\mathrm{P}=$ $0.036 \%)$.

A significant impairment of the renal-function $(P=0.031)$ and liver-function tests with higher level of lactate-dehydrogenase $(L D H)(P<0.001)$, serum bilirubin $(P<0.001)$, alanine-transferase; ALT $(P=0.036)$, and aspartate-aminotransferase, AST $(P=0.022)$ in male patients compared to female patients.

In conclusion, this is the first detailed analysis in the middle east that thoroughly investigate the role of gender in determining the clinical course and severity of COVID-19 infection. Males compared to their age matched females, with same prevalence of comorbidities were more vulnerable to the sever COVID-19 illness with higher probability for ICU admission.

\section{Introduction}

Since the novel coronavirus disease-19 (COVID-19) outbreak in the end of 2019, extra efforts and preparations were made for the identification of risk factors that might be responsible for the poor clinical course and outcome of some patients' subpopulations[1]. Better understanding of such risk factors might be essential to improve our response to the disease pandemic through the active use of the available resources including early access to the health system and the intensive care unit (ICU), and the adoption of more precise and targeted therapeutic strategies [2].

Initial reports identified history of previous chronic illnesses like diabetes mellites (DM), hypertension (HTN) and cardiovascular diseases (CVD) as major risk factors that might predispose to worse clinical outcome[3, 4].

Moreover, demographic data obtained from small scale studies highlighted that even though women and men were infected equally with the disease, the clinical course and the disease burdens was more significant in male patients compared to females[3-5]. Indeed, mortality rates were found to be 
significantly higher in males patients compared to female patients, yet, this rate was found to be significantly variable depending on the demographic features and country from which the results obtained $[6,7]$. This was attributed to gender related social and lifestyle habits including higher rates of alcohol consumption and smoking [8].

Detailed analysis of the gendered dimensions of the COVID-19 infection and its relationship with the demographic, clinical as well as biochemical and radiological findings are still scarce[2].

Therefore, we compared the clinicopathological and demographic as well as the biochemical characteristics of male and female patients with COVID-19 in a case series of 200 patients recruited from Al Kuwait Hospital, Dubai, United Arab Emirates (UAE). According to our knowledge, this is the first detailed analysis in the Middle East that thoroughly investigate the role of gender in determining the clinical course and severity of COVID-19 infection.

\section{Material And Method}

\section{Patients and Data Sources}

Data of COVID-19 positive patients who were admitted to Al Kuwait Hospital, Dubai, UAE in the period between March to April 2020 were retrospectively retrieved. Ethical approval for this study was obtained from Ministry of Health and Prevention (MOHAP) Research Ethics Committee with a number of (MOHAP/DXB-REC/MMM/NO.44/2020). The data of 200 patients (above 18 years) were collected. The demographic and clinical data included main presenting symptoms, risk factors for severe illness including old age, HTN, DM, previous history of CVD, stroke/transient ischemic attack and chronic lung diseases. The radiological findings as well as the laboratory results including blood rheology, inflammatory markers, coagulation profile parameters, liver function and renal function text were extracted for all the study subjects.

\section{Statistical analysis}

For our patient's cohort, the data were tabulated and presented as either mean \pm SD for the continues variables, or percentage for the categorical variables. For statistical analysis, GraphPad prism 7 (GraphPad Software, Inc., San Diego, CA, USA, 2016) software was used. Chi-square test or student's ttest were used to investigate the differences between the males and female patients. P-value of $\leq 0.05$ was used as a cut of value to differentiate between significant or not significant differences.

\section{Results}

Males with COVID-19 infection have more serious clinical course and ICU admission compared to female patients 
Initially we investigated the demographic and clinical features of our cohort stratified according to their gender. Our cohort consisted of 56 females and 144 male patients. The results showed no significant difference in the mean age between females $(44.52 \pm 2.43)$ and male patients $(45.28 \pm 1.15)$ years, $(P=$ 0.750 ) (Table 1). For both genders fever and cough were the main presenting symptom for COVID-19 infection. While it did not reach to statistical significance, our results showed that male patients needed admission after $5.17 \pm 0.29$ days from the onset of their symptoms, in contrast, female patients admitted to hospital $6.12 \pm 0.47$ days after starting their symptoms $(P=0.093)$ (Table 1$)$.

Regarding underlying chronic diseases (i.e. CVD, HTN, DM and chronic lung diseases), both genders showed comparable prevalence of those comorbidities without any significant difference ( $44 \%$ for both, $P=0.970$ ) (Table 1). DM as well as HTN were the most frequent comorbidities seen in both genders. Interestingly, while the age of the patients and incidence of comorbidities were similar, $44.67 \%$ of the male patients were diagnosed with sever-critical pneumonia compared to $23.22 \%$ of the female patient's group $(P=0.001)$. Similarly, the admission to the ICU was significantly higher in the males' group $(26.39 \%)$ compared to only $1.79 \%$ in the females' group $(P<0.001)$ (Table 1$)$. 
Table 1

Demography, clinical features, risk factors and COVID-19 disease activity in the males and the female's patients.

\begin{tabular}{|c|c|c|c|c|c|}
\hline & Female & $\%$ & Male & $\%$ & $\begin{array}{l}P \\
\text { value }\end{array}$ \\
\hline Total & 56 & 28 & 144 & 72 & \\
\hline Age of the patient (years) & $\begin{array}{l}44.52 \\
\pm 2.43\end{array}$ & & $\begin{array}{l}45.28 \\
\pm 1.15\end{array}$ & & 0.750 \\
\hline Time since symptom onset to admission $(\mu \pm$ SD) & $\begin{array}{l}6.12 \pm \\
0.47\end{array}$ & & $\begin{array}{l}5.17 \pm \\
0.29\end{array}$ & & 0.093 \\
\hline \multicolumn{6}{|l|}{ Clinical presentation } \\
\hline Fever & 26 & 46.42 & 81 & 56.25 & 0.211 \\
\hline Cough & 26 & 46.42 & 65 & 45.13 & 0.860 \\
\hline Sore throat & 11 & 19.64 & 18 & 12.5 & 0.190 \\
\hline Diarrhea & 5 & 8.92 & 4 & 2.77 & 0.059 \\
\hline \multicolumn{6}{|l|}{ Comorbidities } \\
\hline $\begin{array}{l}\text { Presence of Comorbidities (CVD, DM, HTN, } \\
\text { stroke/TIA, cancer, chronic lung diseases) }\end{array}$ & 25 & 44.64 & 64 & 44.44 & \multirow[t]{2}{*}{0.970} \\
\hline No comorbidities & 31 & 55.36 & 80 & 55.56 & \\
\hline \multicolumn{6}{|l|}{ Risk factors } \\
\hline Elderly (> 60 years) & 12 & 21.42 & 22 & \multicolumn{2}{|l|}{15.27} \\
\hline CVD & 0 & 0 & 6 & \multicolumn{2}{|l|}{4.16} \\
\hline DM & 13 & 23.21 & 40 & \multicolumn{2}{|l|}{27.78} \\
\hline Hypertension & 14 & $25 \%$ & 43 & \multicolumn{2}{|l|}{29.86} \\
\hline Chronic lung diseases & 3 & 5.35 & 5 & \multicolumn{2}{|l|}{3.47} \\
\hline \multicolumn{6}{|l|}{ Disease severity } \\
\hline Mild-moderate & 43 & 76.79 & 79 & 55.24 & \multirow[t]{3}{*}{0.001} \\
\hline Sever & 12 & 21.43 & 32 & 22.38 & \\
\hline Critical & 1 & 1.79 & 32 & 22.38 & \\
\hline ICU admission & 1 & 1.79 & 38 & 26.39 & 0.000 \\
\hline $\begin{array}{l}\text { COVID-19; novel coronavirus disease }-19 \text {. Data pr } \\
\text { S; mean } \pm \text { standard deviation. CVD; cardiovascular } \\
\text { TIA; transient ischemic attack, ICU; intensive care u }\end{array}$ & $\begin{array}{l}\text { ed numbe } \\
\text { ise, DM; d } \\
\text { old font is }\end{array}$ & $\begin{array}{l}\text { and perc } \\
\text { betes } m \\
\text { he signi }\end{array}$ & $\begin{array}{l}\text { entage }(9 \\
\text { ellitus, } \mathrm{H} \\
\text { cant } \mathrm{p} \mathrm{v}\end{array}$ & $\begin{array}{l}\text { except } \\
\text { j; hypert } \\
\text { ue; }<0.0\end{array}$ & $\begin{array}{l}\text { or } \mu \pm \\
\text { nsion, }\end{array}$ \\
\hline
\end{tabular}




\begin{tabular}{|lccccc|}
\hline & Female & $\%$ & Male & $\%$ & $\begin{array}{l}P \\
\text { value }\end{array}$ \\
\hline No ICU admission & 55 & 98.21 & 106 & 73.61 \\
\hline $\begin{array}{l}\text { COVID-19; novel coronavirus disease - 19. Data presented number and percentage (\%), except for } \mu \pm \\
\text { S; mean } \pm \text { standard deviation. CVD; cardiovascular disease, DM; diabetes mellitus, HTN; hypertension, } \\
\text { TIA; transient ischemic attack, ICU; intensive care unit. Bold font is the significant } p \text { value; }<0.05 .\end{array}$ \\
\hline
\end{tabular}

\section{Male gender showed distinct radiological and laboratory features in the COVID-19 patients compared to female patients}

Interestingly, the present study data showed that evidence of lung damage presented as bilateral airspace consolidation in chest X-ray was evident in $38.89 \%$ of the male patients. This percentage was significantly lower in female patients with only $23.21 \%$ showed evidence of bilateral air space consolidation ( $P=0.036)$ (Table 2$)$. This difference might indicate more sever lung injury in male patients that can be easily detected in the chest $\mathrm{X}$ - ray compared to female patients. Further, evaluation using computed tomography (CT) scan imaging showed evidence of ground glass opacities in nearly similar rate in both genders $(55.35 \%$ in females and $59.02 \%$ in males $)(P=0.630)$ (Table 2$)$.

While the hematological parameters were comparable for both genders with the exception of hemoglobin levels that were significantly higher in male patients $(14.24 \pm 0.13 \mathrm{gm} / \mathrm{dL})$ compared to female patients $(12.24 \pm 0.20 \mathrm{gm} / \mathrm{dL})(P<0.000)$ (Table 2$)$, our results showed a significant deterioration in the renal function test and liver function tests in male patients compared to females. Indeed, the mean level of blood urea was significantly higher in male patients $(6.01 \pm 0.48 \mathrm{mmol} / \mathrm{L})$ compared to female patients $(3.41 \pm 0.20 \mathrm{mmol} / \mathrm{L})(P=0.001)$. Similarly, the serum creatinine levels were also higher in the male patients $(101.8 \pm 5.42 \mathrm{umol} / \mathrm{L})$ compared to females $(61.19 \pm 1.72 \mathrm{umol} / \mathrm{L})(\mathrm{P}<0.001)($ Table 2$)$. This was reflected on the estimated glomerular filtration rate (eGFR) that was significantly lower in male patients $(89.23 \pm 2.29 \mathrm{ml} / \mathrm{min})$ compared to female patients $(103.5 \pm 3.24 \mathrm{ml} / \mathrm{min})(P<0.001)$. Further classification also revealed that while only $1.78 \%$ of the female patients suffer from moderate to severe decline in the eGFR, around $12.5 \%$ of male patients suffer from moderate to severe decline in the eGFR ( $P$ $=0.031)$ (Table 2).

Similarly, the study results showed a significant impairment in the liver function tests in male patients compared to females. This includes the higher levels of serum bilirubin $(12.82 \pm 0.65 \mathrm{umol} / \mathrm{L})$ in male patients compared to females $(7.052 \pm 0.48 \mathrm{umol} / \mathrm{L})(\mathrm{P}<0.0001)$. And, the Alanine transferase (ALT) levels were also higher in male patients $(56.63 \pm 6.02 \mathrm{IU} / \mathrm{L})$ compared to females $(35.86 \pm 3.12 \mathrm{IU} / \mathrm{L})(P=$ 0.036). Aspartate transferase (AST) was also higher in males (45.39 $\pm 4.61 \mathrm{IU} / \mathrm{L})$ compared to females $(28.09 \pm 2.02 \mathrm{IU} / \mathrm{L})(\mathrm{P}=0.022)($ Table 2$)$.

Moreover, lactate dehydrogenase (LDH) level was significantly upregulated in male patients $(342.3 \pm$ $17.03 \mathrm{IU} / \mathrm{L})$ compared to females $(235.3 \pm 13.58 \mathrm{IU} / \mathrm{L})(\mathrm{P}<0.000)($ Table 2$)$. 
Table 2

Radiological findings, laboratory values and estimated glomerular filtration rate differences between males and females COVID-19 cases

\begin{tabular}{|c|c|c|c|c|c|}
\hline Radiological findings & Female & $\%$ & Male & $\%$ & value \\
\hline Bilateral air space consolidation & 13 & 23.21 & 56 & 38.89 & $\begin{array}{l}P= \\
0.036\end{array}$ \\
\hline $\begin{array}{l}\text { Bilateral peripheral ground glass opacities (CT } \\
\text { scan) }\end{array}$ & 31 & 55.35 & 85 & 59.02 & $\begin{array}{l}P= \\
0.630\end{array}$ \\
\hline \multicolumn{6}{|l|}{ Laboratory findings } \\
\hline Hemoglobin (gm/dL) & \multicolumn{2}{|l|}{$\begin{array}{l}12.24 \pm \\
0.20\end{array}$} & \multicolumn{2}{|l|}{$\begin{array}{l}14.24 \pm \\
0.13\end{array}$} & 0.000 \\
\hline WBC (x10(3)/mcL) & \multicolumn{2}{|l|}{$9.30 \pm 2.8$} & \multicolumn{2}{|l|}{$\begin{array}{l}7.92 \pm \\
0.31\end{array}$} & 0.452 \\
\hline Platelet count (x10(3)/mcL) & \multicolumn{2}{|l|}{$\begin{array}{l}229.5 \pm \\
9.47\end{array}$} & \multicolumn{2}{|l|}{$\begin{array}{l}229.3 \pm \\
6.23\end{array}$} & 0.986 \\
\hline INR & \multicolumn{2}{|l|}{$\begin{array}{l}1.02 \pm \\
0.03\end{array}$} & \multicolumn{2}{|l|}{$\begin{array}{l}1.04 \pm \\
0.01\end{array}$} & 0.243 \\
\hline Prothrombin time (seconds) & \multicolumn{2}{|l|}{$\begin{array}{l}13.63 \pm \\
1.84\end{array}$} & \multicolumn{2}{|l|}{$\begin{array}{l}11.91 \pm \\
0.09\end{array}$} & 0.156 \\
\hline D-dimer & \multicolumn{2}{|l|}{$\begin{array}{l}1.42 \pm \\
0.41\end{array}$} & \multicolumn{2}{|l|}{$\begin{array}{l}1.61 \pm \\
0.43\end{array}$} & 0.798 \\
\hline $\mathrm{CRP}(\mathrm{mg} / \mathrm{l})$ & \multicolumn{2}{|l|}{$\begin{array}{l}20.48 \pm \\
5.5\end{array}$} & \multicolumn{2}{|l|}{$\begin{array}{l}54.64 \pm \\
6.3\end{array}$} & 0.001 \\
\hline Urea (mmol/L) & \multicolumn{2}{|l|}{$\begin{array}{l}3.41 \pm \\
0.20\end{array}$} & \multicolumn{2}{|l|}{$\begin{array}{l}6.01 \pm \\
0.48\end{array}$} & 0.001 \\
\hline Creatinine (umol/L) & \multicolumn{2}{|l|}{$\begin{array}{l}61.19 \pm \\
1.72\end{array}$} & \multicolumn{2}{|l|}{$\begin{array}{l}101.8 \pm \\
5.42\end{array}$} & 0.000 \\
\hline eGFR (ml/min) & \multicolumn{2}{|l|}{$\begin{array}{l}103.5 \pm \\
3.24\end{array}$} & \multicolumn{2}{|l|}{$\begin{array}{l}89.23 \pm \\
2.29\end{array}$} & 0.000 \\
\hline \multicolumn{6}{|l|}{ eGFR classification (ml/min) } \\
\hline $\begin{array}{l}\text { Stage } 1 \text { (kidney damage with normal or } \\
\text { increased GFR > 90) }\end{array}$ & 40 & 71.42 & 74 & 51.38 & 0.031 \\
\hline \multicolumn{6}{|c|}{$\begin{array}{l}\text { COVID-19; novel coronavirus disease }-19 \text {. Results of t-test for the differences between continuous } \\
\text { variables; presented as mean } \pm \text { standard deviation, and of the Chi- } 2 \text { test for the differences between } \\
\text { categorical variables; presented as number (percentage; \%). CT; computerized tomography, INR; } \\
\text { international normalized ratio, CRP; C-reactive protein, eGFR; estimated glomerular filtration rate, LDH; } \\
\text { lactate dehydrogenase, ALT; alanine transferase, AST; aspartate transaminase, ALP; alkaline } \\
\text { phosphatase. Significant p value }(<0.05) \text { in bold. }\end{array}$} \\
\hline
\end{tabular}




\begin{tabular}{|c|c|c|c|c|c|}
\hline Radiological findings & Female & $\%$ & Male & $\%$ & $\begin{array}{l}P \\
\text { value }\end{array}$ \\
\hline $\begin{array}{l}\text { Stage } 2 \text { (kidney damage with mildly decreased } \\
\text { GFR 60-89) }\end{array}$ & 15 & 26.78 & 52 & 36.11 & \\
\hline Stage 3 (moderately decreased GFR 30-59 & 1 & 1.78 & 14 & 9.72 & \\
\hline Stage $4 \& 5$ (severely decreased GFR $<29$ ) & 0 & $0 \%$ & 4 & 2.78 & \\
\hline LDH (IU/L) & $\begin{array}{l}235.3 \pm \\
13.58\end{array}$ & & $\begin{array}{l}342.3 \pm \\
17.03\end{array}$ & & 0.000 \\
\hline Serum bilirubin (umol/L) & $\begin{array}{l}7.052 \pm \\
0.48\end{array}$ & & $\begin{array}{l}12.82 \pm \\
0.65\end{array}$ & & 0.000 \\
\hline ALT (IU/L) & $\begin{array}{l}35.86 \pm \\
3.12\end{array}$ & & $\begin{array}{l}56.63 \pm \\
6.02\end{array}$ & & 0.036 \\
\hline AST $(U / L)$ & $\begin{array}{l}28.09 \pm \\
2.02\end{array}$ & & $\begin{array}{l}45.39 \pm \\
4.61\end{array}$ & & 0.022 \\
\hline ALP (IU/L) & $\begin{array}{l}80.61 \pm \\
3.53\end{array}$ & & $\begin{array}{l}78.91 \pm \\
2.75\end{array}$ & & 0.731 \\
\hline Albumin(gm/L) & $\begin{array}{l}34.03 \pm \\
0.84\end{array}$ & & $\begin{array}{l}33.75 \pm \\
0.57\end{array}$ & & 0.792 \\
\hline \multicolumn{6}{|c|}{$\begin{array}{l}\text { COVID-19; novel coronavirus disease }-19 \text {. Results of t-test for the differences between continuous } \\
\text { variables; presented as mean } \pm \text { standard deviation, and of the Chi- } 2 \text { test for the differences between } \\
\text { categorical variables; presented as number (percentage; \%). CT; computerized tomography, INR; } \\
\text { international normalized ratio, CRP; C-reactive protein, eGFR; estimated glomerular filtration rate, LDH; } \\
\text { lactate dehydrogenase, ALT; alanine transferase, AST; aspartate transaminase, ALP; alkaline } \\
\text { phosphatase. Significant p value }(<0.05) \text { in bold. }\end{array}$} \\
\hline
\end{tabular}

\section{Discussion}

Since the beginning of COVID-19 outbreak in the end of 2019, the wide range of its symptoms as well as the diversity in its clinical course and laboratory findings highlighted the need of better understanding of the factors that might affect this diversity[9]. Indeed, while most of the patients suffer from only mild symptoms, a small fraction of patients suffers from more sever and critical form of this disease[10]. The success in our response to this pandemic depend mainly on the identification of the risk factors that might determine the prognosis and clinical outcome of different patients subpopulations[1].

In the current study we investigated the association between COVID-19 patients' gender and different demographic, clinical, biochemical and radiological findings in our patient cohort that consisted of 200 patients recruited from Al Kuwait Hospital, Dubai, UAE. Indeed, this is the first detailed analysis in the middle east and one of only few reports in the world that thoroughly investigate the role of gender in determining the clinical course and severity of COVID-19 infection. Our results showed higher prevalence of COVID-19 infection in male patients (72\%) compared to females (28\%). This finding differ from previous reports that showed nearly similar prevalence of the disease among both genders $[2,4,8,11]$. 
Interestingly, while our results showed no difference in the age groups between the two genders, male patients were highly vulnerable to the sever-critical form of the COVID-19 disease and to the ICU admission compared to female patients.

This goes with previous reports that also showed male sex as an independent risk factor for critical and refractory form of the disease compared to women[2,12,13]. Moreover, the fatality rates were found to be also different with male patients have 2-3 times higher mortality rates compared to female patients[6].

Our finding that around $40 \%$ of male patients suffer from bilateral airspace consolidation on the plan Xray at admission to hospital compared to only $23 \%$ in female patient further confirm the fact that male patients are usually presented with more severe form of the disease. These finding goes with other report that found radiological evidence of more extensive lung damage in COVID-19 male patients when compared to female patients despite the similarity in the age group and symptoms onset[14].

The multiple organ injury that we observed in the male patients can explain this worse clinical course. This was evident with the significant increase in the blood urea and serum creatinine in the male patients compared to females which led to significant deterioration in the eGFR levels. Interestingly, while only $1.78 \%$ of female patients suffer from moderate-sever deterioration in the eGFR, $12.5 \%$ of male patients had moderate to severe reduction in the GFR. This clearly demonstrated a form of acute kidney injury in those patients compared to female patients. Previous reports showed acute kidney injury (AKI) as a common finding in COVID-19 patients presented with critical illness[15].

In addition, the abnormal liver tests that were significantly higher in male patients compared to female patients highlight the possibility of more evident liver injury in male patients compared to female patients. Presence of renal function and liver function impairment indicate the multiorgan damage caused by COVID-19.

An important finding in this report is the fact that both males and female patients group shared many of the demographic as well as the epidemiological characteristics. This includes comparable age group and predisposing risk factors; however, the clinical course and the prognosis was significantly different. There are many explanations that might explain this variability. This includes some behavior factors like smoking and alcohol consumption [16]. Additionally, sex-based immunological differences[13] and gender-defined genetic polymorphisms [17] were also proposed to play a role in the different outcome between both genders in response to COVID-19 infection. Moreover, our group also proposed the differential expression of some genes including genes involved in the regulation of hydrolase activity and Angiotensin II Receptor Type 1 (AGTR1), essential for (ACE2) activity modulation, to be responsible for this variation[18].

\section{Conclusion}

The present study results highlight the need of urgent efforts to investigate the molecular mechanisms that might attributed to this gender variation. Better understanding of such factors might help in 
improving our response to the COVID19 pandemic through identification of high-risk groups and the adoption of more targeted approached to treat different patients' subpopulations. Also, such approach might be essential for the discovery of new molecules and pathways that might be used a predictive markers or therapeutic targets with the aim of improving patient outcome.

\section{Declarations}

Ethical Approval and Consent to participate: The study was approved by the Scientific Research Committee MOHAP/DXB-REC/MMM/NO.44/2020 and certify that the study was performed in accordance with the ethical standards as laid down in the 1964 Declaration of Helsinki and its later amendments ethical standards.

Consent for publication: All authors have agreed to the publication and to be accountable for all aspects of the work in ensuring that questions related to the accuracy or integrity of any part of the work are appropriately investigated and resolved.

Data availability statement: Data can be provided upon request on individual basis

but it is not available publicly.

Competing interests: All authors declare no conflict of Interest related to the current manuscript.

Funding: no funding available for all authors.

Author Contribution Statement: All authors have contributed equally

Acknowledgment: We would like to thank all our patients for their patience. Also, we highly appreciate our colleagues and staff for their tremendous hard work during this crisis. In addition, we extend our gratitude to all staff at the Research Ethics Committee and the Information Technology Department for their help.

\section{Authors' information: as per title page}

\section{References}

1. Tian J, et al., Clinical characteristics and risk factors associated with COVID-19 disease severity in patients with cancer in Wuhan, China: a multicentre, retrospective, cohort study. Lancet Oncol, 2020.

2. Jin JM, et al. Gender Differences in Patients With COVID-19: Focus on Severity and Mortality. Front Public Health. 2020;8:152.

3. Novel Coronavirus Pneumonia Emergency Response Epidemiology. T., [The epidemiological characteristics of an outbreak of 2019 novel coronavirus diseases (COVID-19) in China]. Zhonghua Liu Xing Bing Xue Za Zhi. 2020;41(2):145-51.

4. Zhou F, et al. Clinical course and risk factors for mortality of adult inpatients with COVID-19 in Wuhan, China: a retrospective cohort study. Lancet. 2020;395(10229):1054-62. 
5. Huang C, et al. Clinical features of patients infected with 2019 novel coronavirus in Wuhan, China. Lancet. 2020;395(10223):497-506.

6. Porcheddu R, et al. Similarity in Case Fatality Rates (CFR) of COVID-19/SARS-COV-2 in Italy and China. J Infect Dev Ctries. 2020;14(2):125-8.

7. de Groot NG, Bontrop RE, COVID-19 pandemic: is a gender-defined dosage effect responsible for the high mortality rate among males? Immunogenetics, 2020.

8. Wenham C, et al. COVID-19: the gendered impacts of the outbreak. Lancet. 2020;395(10227):846-8.

9. Guan WJ, et al. Clinical Characteristics of Coronavirus Disease 2019 in China. N Engl J Med. 2020;382(18):1708-20.

10. Wu Z, McGoogan JM. Characteristics of and Important Lessons From the Coronavirus Disease 2019 (COVID-19) Outbreak in China: Summary of a Report of 72314 Cases From the Chinese Center for Disease Control and Prevention. JAMA, 2020.

11. Li Q, et al. Early Transmission Dynamics in Wuhan, China, of Novel Coronavirus-Infected Pneumonia. N Engl J Med. 2020;382(13):1199-207.

12. Mo P, et al., Clinical characteristics of refractory COVID-19 pneumonia in Wuhan, China. Clin Infect Dis, 2020.

13. Chen N, et al. Epidemiological and clinical characteristics of 99 cases of 2019 novel coronavirus pneumonia in Wuhan, China: a descriptive study. Lancet. 2020;395(10223):507-13.

14. Dangis A, et al., Impact of gender on extent of lung injury in COVID-19. Clin Radiol, 2020.

15. Hirsch JS, et al., Acute kidney injury in patients hospitalized with COVID-19. Kidney Int, 2020.

16. The L. The gendered dimensions of COVID-19. Lancet. 2020;395(10231):1168.

17. Zeng $\mathrm{F}$, et al., A comparison study of SARS-CoV-2 IgG antibody between male and female COVID-19 patients: a possible reason underlying different outcome between gender. medRxiv 2020. 2020.03.26.20040709.

18. Hachim IY, et al., The Molecular Basis of Gender Variations in Mortality Rates Associated with the Novel Coronavirus (COVID-19) Outbreak. Preprints, 2020.

\section{Supplementary Files}

This is a list of supplementary files associated with this preprint. Click to download.

- coidisclosuregender.pdf 